\title{
The influence of the injection molding on mechanical properties of EPDM rubber testing samples
}

\author{
Adam Skrobak $^{\mathrm{a}}$, Michal Stanek, David Manas, Martin Ovsik, Vojtech Senkerik, Martin Reznicek and \\ Lenka Hylova \\ Tomas Bata University in Zlin, TGM 5555, 76001 Zlin, Czech Republic
}

\begin{abstract}
The paper deals with the impact of the production process on mechanical properties (tensile strength and tear strength) of a standardized testing sample made of rubber compound based on ethylene propylene diene rubber produced by injection molding in comparison with a sample produced by classic preparation (cutting out a compression molded plate) according to the standard ISO 23529.
\end{abstract}

Keywords: injection molding, compression molding, mechanical properties, rubber compound.

\section{Introduction}

Control of the mechanical properties of rubber products produced by injection molding is mostly performed on testing samples produced in another way, i.e. cutting off a compression molded plate. This distinct way of producing testing samples and final products can result in different mechanical properties. Injection molding of rubber compounds is used mainly in the automotive industry to produce a large assortment of products which are more demanding as for the shape and dimensional precision. Injection molding is most effective in continuous production operations. Injection molding differs from compression molding mainly in different remolding of the material. During the injection molding the rubber compound comes in the mold cavity, having been preheated to a higher temperature, i.e. with lower viscosity, and owing to the injection speed and pressure it is subject to higher shear stress. This distinct way of remolding can result in a different disposition of macromolecules in the material structure and different internal strain, which has an impact on the resulting properties of the final product [1-2].

\section{Experimental}

For this research, a rubber compound on based ethylene propylene diene rubber (curing agent - sulphur) appointed for production of automotive parts was chosen. Approximate composition of the compound is shown in Table 1 . This compound shows sufficient scorch time and fluidity, which were verified by a measurement on RPA (Rubber Process Analyzer). The curing temperature $170{ }^{\circ} \mathrm{C}$ was chosen for both technologies (compression molding and injection molding).

${ }^{a}$ Corresponding author: skrobak@ft.utb.cz 
Table 1. Vulcanization specification for $160^{\circ} \mathrm{C}$.

\begin{tabular}{|c|c|}
\hline Min. torque $\mathrm{S}^{\prime}$ & $2.11 \mathrm{dN} . \mathrm{m}$ \\
\hline Max. torque $\mathrm{S}^{\prime}$ & $20.24 \mathrm{dN} . \mathrm{m}$ \\
\hline Scorch time $\left(\mathrm{t}_{\mathrm{S}}\right)$ & $0.54 \mathrm{~min}$ \\
\hline $10 \%$ cure $\left(\mathrm{t}_{10}\right)$ & $1.04 \mathrm{~min}$ \\
\hline $50 \%$ cure $\left(\mathrm{t}_{50}\right)$ & $3.26 \mathrm{~min}$ \\
\hline $90 \%$ cure $\left(\mathrm{t}_{90}\right)$ & $12.16 \mathrm{~min}$ \\
\hline
\end{tabular}

For this research, the mechanical tension test according to the standard ISO 37 was chosen. The standard also prescribes the shapes and dimensions of testing samples. To perform this test, the testing sample dumbbell - type 1 (Fig. 1a) has been selected. Another test confirming the mechanical properties is the test determining tear strength according to the standard ISO 34-1. To perform this test, the samples crescent, graves and trousers were chosen (Fig. 1b, c, d).

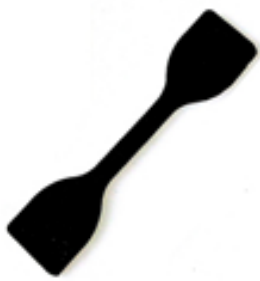

a)

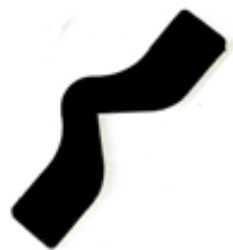

b)

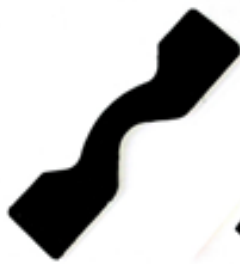

c)

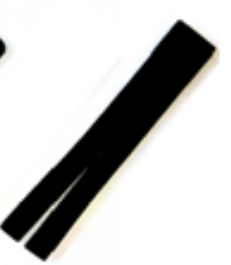

d)

Figure 1. Test samples: a) dumbbell (type 1); b) crescent; b) graves; d) trouser.

To carry out the experiment, it was necessary to design and produce an injection mold for all types testing samples. The designed mold includes a universal frame, into which mold plates for given shapes of samples are inserted as necessary. The production of samples was carried out as follows. In case of compression molding, it was first necessary to remold the rubber compound with the assistance of a roll mill and to prepare the required thickness. Next the raw products were cut out in shape of the sheet. Then the raw products were inserted into the pre-heated molding machine and the sheets with dimensions 120 $\mathrm{x} 120 \mathrm{~mm}, 2 \mathrm{~mm}$ thick, were compression molding. Finally the testing rubber samples were cut out with the assistance of a shape knife, in the line of the material orientation to prevent mistaking the anisotropy direction. In case of injection molding the pre-plasticated compound, $4 \mathrm{~mm}$ thick, was cut into belts $3 \mathrm{~cm}$ wide to fill in the injection molding machine REP V27/Y125. Then the injection molding itself was performed. The injection molded samples after opening the mold are demonstrated in Fig. 2. After injection molding the runner system was removed. The samples were produced from one charge of rubber compound.
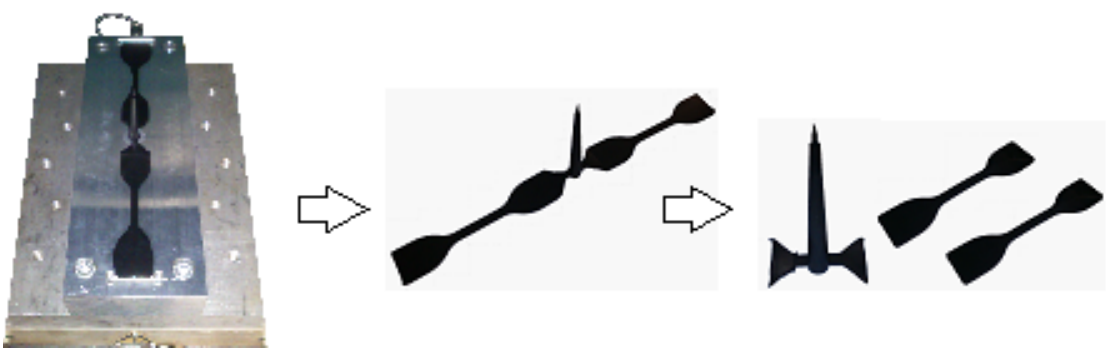

Figure 2. Production of test samples by injection molding. 
Table 2. Process conditions of production.

\begin{tabular}{|l|l|c|c|}
\hline \multicolumn{2}{|c|}{} & Compression molding & Injection molding \\
\hline \multirow{2}{*}{ Temperature } & Mold & \multicolumn{2}{|c|}{$170{ }^{\circ} \mathrm{C}$} \\
\cline { 2 - 4 } & Rubber compound & $23{ }^{\circ} \mathrm{C}$ & $100{ }^{\circ} \mathrm{C}^{*}$ \\
\hline \multirow{2}{*}{ Pressure } & Closing & $20 \mathrm{MPa}$ & - \\
\cline { 2 - 4 } & Injection & - & $20 \mathrm{MPa}$ \\
\hline Curing times & $4 ; 6 ; 8 ; 10 ; 12 ; 14 ; 16 ; 18 ; 20 \mathrm{~min}$ \\
\hline
\end{tabular}

[Time of pre-heating the rubber compound in plastication unit was 30 seconds.]

\section{Results and discussion}

The measured values of the test which determines the tensile stress-strain properties (Fig. 3) showed that with the growing curing time, also the tension necessary to break a testing sample grows. This confirms the fact that with longer curing period, the cured rubber achieves better tensile properties. With longer curing time the percentage of cross links created in the material structure grows, which is demonstrated in the ability to resist bigger tensile force. At the same time the material elongation increases. The results also show that samples produced by injection molding have higher strength (by $2.5 \%$ in approximately optimal curing time of 12 minutes) than compression molded samples.

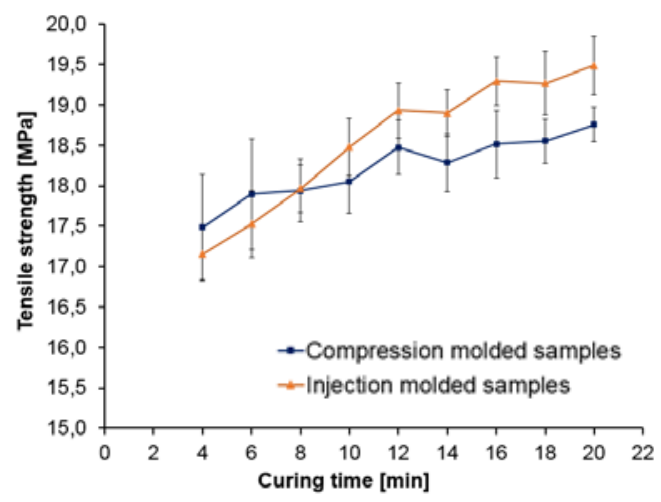

Figure 3. Tensile strength vs. curing time.

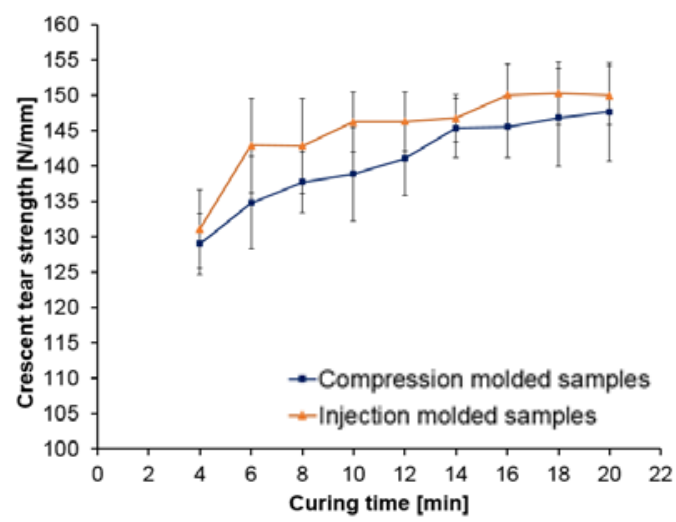

Figure 5. Crescent tear strength vs. curing time.

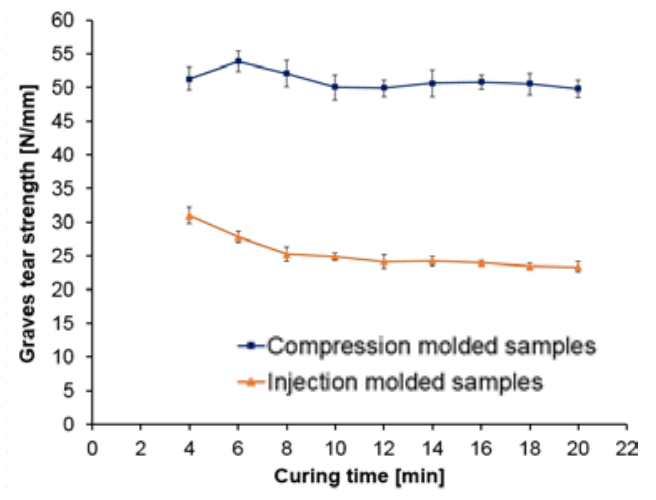

Figure 4. Graves tear strength vs. curing time.

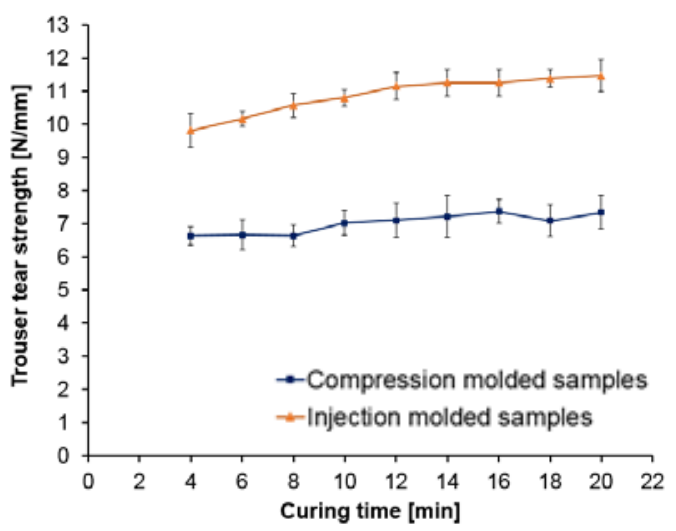

Figure 6. Trouser tear strength vs. curing time.

The tear strength of the injection molded graves samples (Fig. 4) decreased during the optimum cure by $48.3 \%$ compared to the compression molded samples. To the contrary the tear strength of the injection molded crescent samples (Fig. 5) during the same curing time increased by $3.7 \%$ and in case of 
the trouser tear strength (Fig. 6) the difference is $55 \%$ in favor of injected samples. The crescent samples do not have significant notches that would contribute to concentration of the tension. During stretching the deformation energy is mainly used for stretching of the sample rather than for broadening the cracking. This is why the tear strength of this type of sample reaches generally higher values.

The obtained results of tests performed on the produced testing samples showed certain differences in mechanical properties. To provide clearer evaluation there is a table (Tab. 4) which shows the increase $(+)$ or decrease $(-)$ in percentage of the measured properties of injected samples with respect to the samples produced by the standard method. The table evaluates the quantities measured in the time close to the optimum cure (12 minutes).

Table 3. The relative increase (decrease) in the measured properties of injection molded samples.

\begin{tabular}{|c|c|}
\hline Measurement property & Injection molding \\
\hline Tensile strength & $+2,5 \%$ \\
\hline Graves tear strength & $-48,3 \%$ \\
\hline Crescent tear strength & $+3,7 \%$ \\
\hline Trouser tear strength & $+55 \%$ \\
\hline
\end{tabular}

\section{Conclusions}

The results of the performed tests showed that the standard preparation method used in case of testing samples (cutting out of the compression molded plate) can be applied also on compounds appointed to the production of injected products. However, the properties of samples produced by this method are not wholly objective, mainly in case of tear strength. The results of the tensile test prove that in the optimum of cure the injected samples have higher tensile strength than samples produced by a standard method. This is probably caused by a higher degree of cross-linking. This also supports the hypothesis that owing to pre-heating of the compound in the plasticizing unit of the injection molding machine the degree of cross-linking is in case of injected samples within the same curing time higher than in case of samples produced by the standard procedure, like compression molding. The stated results of this research open new possibilities of the testing samples preparation in rubber-making industry, mainly in companies where the injection molding technology is used. It was determined that the preparation method of injection molded samples is viable and for testing of rubber compounds, or products made of such compounds, is more evident than in case of samples prepared by the standard method used up to the present time. In view of the results of this research, when producing injection molded rubber products, it is also recommended to use injection molded testing samples to test their tear properties.

\section{Acknowledgments}

This work was supported by the Ministry of Education, Youth and Sports of the Czech Republic within the National Sustainability Programme project No.LO1303 (MSMT-7778/2014) and also by the European Regional Development Fund under the project CEBIA-Tech No. CZ.1.05/2.1.00/03.0089 and the internal grant of TBU in Zlin No.IGA/FT/2016/010 are funded from the resources of specific university research and by the Ministry of Education, Youth and Sports of the Czech Republic. 


\section{References}

1. J. A. Sezna, Rubber testing for injection molding, Rubber World. 207 (4) (1993) 12-19.

2. Arrillaga, A., Zaldua, A. M., \& Farid, A. S. Evaluation of injection-molding simulation tools to model the cure kinetics of rubbers. J. of App. Pol. Sci. 123 (3) (2012) 1437-1454. 